\title{
The Role of German Academic Medicine and Science in the Medical Crimes of the Third Reich and the Shoah: The Continuing Legacy
}

\author{
William Seidelman, M.D.
}

Despite the revelations of the Nuremberg Medical Trial and subsequent prosecutions, the reality is that, with particular respect to medicine and the role of leading academic and scientific institutions during the so-called "Third Reich," the postwar period war was marked by a "Great Silence." With few exceptions, this silence continued until the 1980's, when increasing systematic scholarly research and inadvertent discoveries revealed the significant role played by the German and Austrian medical profession during the Nazi period and the Shoah. The discoveries included body parts of victims of Nazi terror in the collections of university institutes of anatomy and scientific research. The Pernkopf Atlas of Human Anatomy represents a legacy from Nazi medicine. Although it includes images from Nazi victims, its accuracy makes it a valued resource in surgery. The Vienna Protocol is a new halachic responsum on the question of what to do with newly discovered remains from Nazi victims and their data, and can provide guidance in the ethical reasoning on whether to use the Pernkopf atlas.

OPEN ACCESS

On behalf of my participating colleagues and myself, I want to express our appreciation to the organizers of Holocaust Education Week for accommodating our program at this significant event. I also want to express our gratitude to Dr. Leila Lax for her energy and leadership in championing our proposal.

I am speaking from the library of the cultural center Bet HaGat in the Jerusalem neighborhood of Ein Kerem, Israel. As some of you are aware, my wife Racheline and
I, upon our retirement 12 years ago, moved to Israel where our three daughters had chosen to make their lives. While I now make my life in Israel, this work began in Canada about four decades ago. I need to acknowledge my former colleagues at McMaster University and the North Hamilton Community Health Centre, who selflessly supported my early efforts. Three people who played key roles include; Professor Carl Moore, the then chairman of the Dept. of Family Medicine; the late Prof. Charles Roland who was the first Hannah Professor of the History of Medicine at McMaster and Professor Michael Kater, the eminent social historian of modern Germany from York University whom I first met at McMaster during his year as Hannah Visiting Professor in the History of Medicine.

After I moved to the University of Toronto in 1994, my Toronto colleagues continued to provide significant support. They included the university Dept. of Family and Community Medicine led by Prof. Walter Rosser and the St. Michael's Hospital Health Centre on Sherbourne St. then led by Prof. Philip Berger.

The move to Toronto in 1994 coincided with the emergence of the controversy over the Pernkopf Atlas of Human Anatomy, which is a focus of today's discussion. I must also acknowledge the critical help of Archie Rabinowitz, and his late father, Morris, who gifted Prof. Israel and me with translations of German language documents. I also want to recognize the role of Baycrest Center and the Holocaust Resource Project led by Dr. Paula David and the guidance of Dr. Nahum Berlat, of Blessed Memory.

My own work began with a history of medicine journal club organized by Prof. Roland. A critical juncture was reached around 1985 when Prof. Kater joined us at McMaster. Prof. Kater has played an essential role in my work until this very day. 


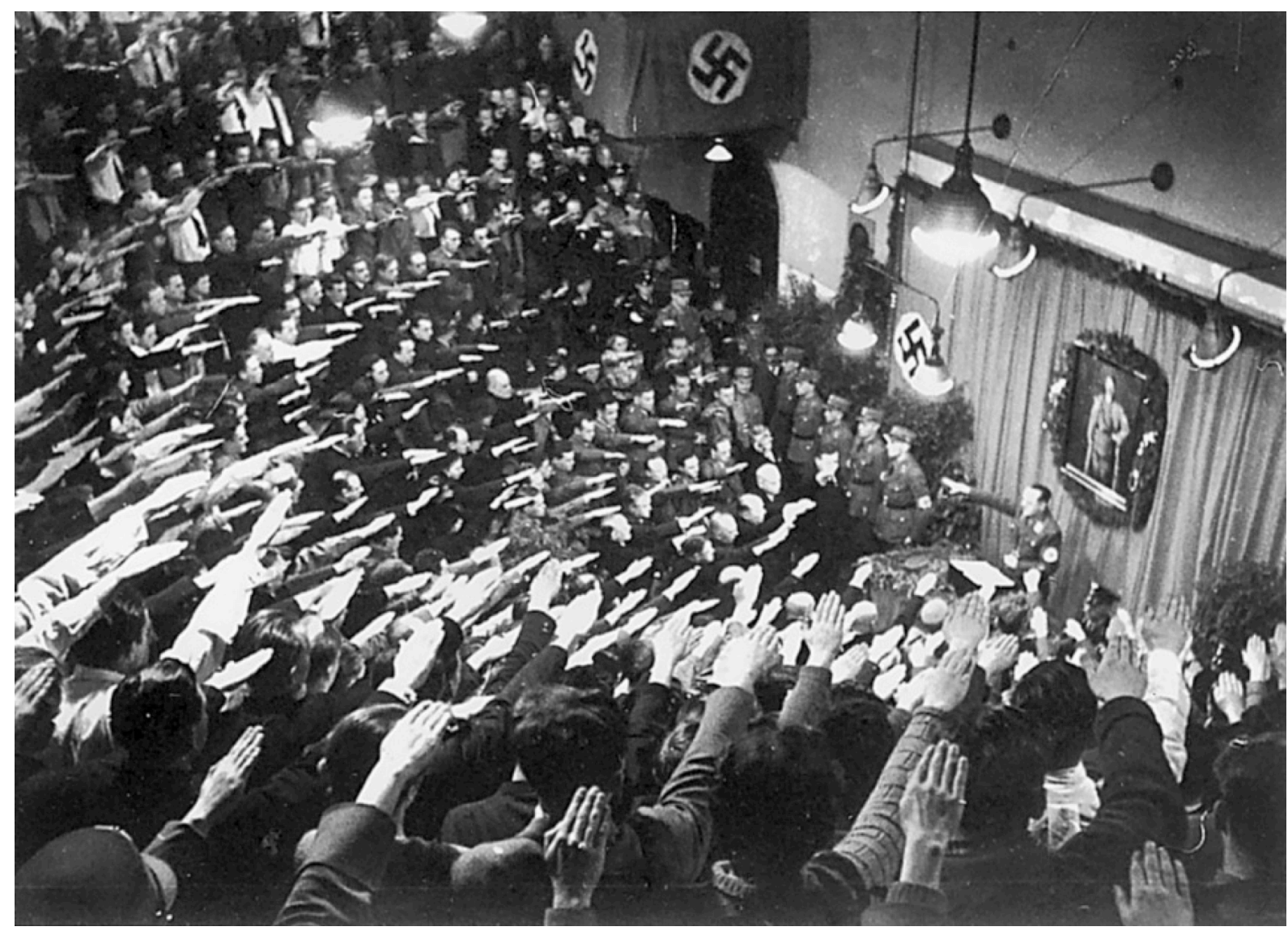

Photo from 1938 depicts an assembly of the Faculty of Medicine of the University of Vienna under its newly appointed dean, Prof. Eduard Pernkopf. This followed the annexation of Austria into Nazi Germany that occurred in March 1938. Licensed and used with permission of the Österreichische Nationalbibliothek (Austrian National Library, Vienna, Austria).

In my early explorations of the subject of medicine in Nazi Germany I came to the realization that the academic and professional elite, including renowned universities and research institutes, played a decisive role in the evolution of the health policies and practices of the Nazi regime. These included: the eugenic and racist transformation of the health care system; the planning and implementation of the programs of murder of people diagnosed with neurological and psychiatric disorders; and the inhuman exploitation of captive victims before their deaths as well as after. This was my suspicion at the time, but a great silence prevailed within and among those institutions where people protected themselves and their colleagues and teachers.

The silence began to break during the 1980's when the first material evidence was discovered by the German historian Dr. Götz Aly. (Aly, 1988) Aly laid open the continued use of brain specimens from murdered victims of the Nazi "euthanasia" program. The specimens were found in the collection of the Max Planck Institute for Brain Research in Frankfurt am Main. The specimens had originally been collected during the war by the eminent neuropathologist, Professor Julius Hallervorden, in his capacity as a senior official with the antecedent KaiserWilhelm Institute for Brain Research in Berlin-Buch. At the end of the war Hallervorden acknowledged,

unapologetically, collecting the brains of victims of the Nazi "euthanasia" killing program.

In 1990 the specimens discovered in Frankfurt were secretly buried at a cemetery in Munich. Despite the Max Planck Society's international reputation as a world leader in research and science, absolutely no research or documentation was undertaken or published on the specimens by this eminent research organization. (Seidelman, 2012; Weindling, 2012) There was no public documentation on the victims or their fate. Ten years after the burial, the Max Planck Society acknowledged the role of the antecedent Kaiser-Wilhelm organization, 
in the exploitation of the "euthanasia" killing program with the acquisition of the brain specimens. (Ter Meulen, 2010) It was almost another two decades before the Max Planck Society undertook a serious exploration of the victims and their fate. This research and documentation project began last year, in $\mathbf{2 0 1 8}$, as a consequence of more recent discoveries of similar misbegotten specimens in Max Planck institutes in Munich and Berlin. It only took 28 years!

Around the same time as Götz Aly's discoveries of the Frankfurt specimens, it was revealed that the University of Tübingen's Institute of Anatomy held specimens in its collection from victims of Nazi terror. In contrast to the Max Planck Society, the University of Tübingen undertook an examination of the collection of the Institute of Anatomy and other University departments. That examination was a consequence of a student protest and included the involvement of experts from outside the university. (Seidelman, 2012) The final report revealed that the bodies of hundreds of foreign nationals and Germans were delivered to the Tübingen anatomy institute. These ill-fated victims had been convicted and executed for political crimes, as well as such offences as stealing food or socializing with German women.

The report of the Tübingen investigation established an important example that would, a few years later, play an important role in a future investigation namely, the University of Vienna. Despite international publicity about these findings and assertions by various levels of the Federal and state governments in the former West Germany, there was apparently no full-scale official investigations with outside experts other than at Tübingen. One notable exception occurred later at the University of Jena in the former East Germany. (Redies et al., 2015)

The political situation changed dramatically with the fall of the Berlin Wall in 1989 and the unification of the, now former, German Democratic Republic with the Federal Republic. As a result of these profound political events, people had other things on their minds besides anatomical specimens from long forgotten Nazi victims.

A major shift began in 1994 when a maxillo-facial surgeon by the name of Prof. Howard Israel, then of Columbia University Faculty of Dentistry in New York, began to examine the origins of the anatomical atlas that had been his constant companion since he received the atlas as a gift from his wife during their student days.
(Israel and Seidelman, 1996) That atlas, which Prof. Hildebrandt will discuss in greater detail, is the, now infamous, Pernkopf Atlas of Human Anatomy.

Before undertaking a surgical procedure, Prof. Israel would consult the Pernkopf atlas because of the detail and accuracy of its imagery. Around 1994 a colleague of Israel's, who observed him studying the atlas, mentioned that Pernkopf had been a Nazi. This remark prompted Israel to examine the original publication in the university library. Prof. Israel took special note of two things: first the signatures in the form of Nazi symbols, in particular the Swastika and the infamous double "s" symbol of the SS terror organization. Prof. Israel observed that the hair of some subjects appeared to have been roughly shorn resembling that of a prisoner. Based on these findings, Israel asked if the subjects could have been Nazi victims. Israel then undertook to find out more. His search serendipitously led him to me.

Prof. Israel and I were not the first to raise questions about Prof. Pernkopf or his atlas. What was unique about our role was the actions we took to bring pressure on the Austrian authorities to undertake an investigation based on the model of the University of Tübingen.

After reviewing Howard Israel's documentation, I suggested, based on my previous experience with institutions in Germany, that if he or I were to write to the Vienna and Austrian authorities on this issue, our inquiries would likely be dismissed or ignored. I recommended that we attempt to have a major Holocaust documentation centre join the effort with the view that a query from an internationally renowned Holocaust documentation center was unlikely to be ignored or dismissed.

Fortunately, the Israel Holocaust and Remembrance Authority, Yad Vashem, responded to our request to lead the effort to write to the Vienna and Austrian authorities. At a meeting in December 1994, Yad Vashem agreed to formally request an investigation based on the model of the University of Tübingen. The correspondence was signed on behalf of Yad Vashem by the then vice-Chair, the late Ambassador Rueven Dafni, who was succeeded by Ambassador Yohanan Bein.

The Faculty of Medicine of the University of Vienna was then part of the University of Vienna. In 2004 it became a separate university now known as the Medical University of Vienna. The university Rector in 1995, Prof. Alfred Ebenbauer, was a scholar of Medieval Studies. Rector 
Ebenbauer referred the questions raised by Yad Vashem to the Faculty of Medicine and the Institute of Anatomy. To make a long story short, people responding to the $\mathrm{Yad}$ Vashem queries via Rector Ebenbauer did not tell the truth. Professor Ebenbauer did not have an easy time in getting the assistance of his colleagues in the medical faculty. Finally, after a letter from Yad Vashem dated July 31, 1995, detailing the inconsistencies, Prof. Ebenbauer realized that his own faculty had been lying to him and said so publicly. Ebenbauer then ordered a Senate Inquiry into Anatomy in Vienna from 1938, chaired by a historian outside the Faculty of Medicine. That investigation began in April 1997 with the final report issued in October 1998. (Angetter, 2000) The Vienna research project determined that the bodies of 1377 people, most of whom having been executed on the guillotine in the Vienna Regional Court and their cadavers delivered to the anatomical institute. It is believed that a number of those victims are portrayed in the atlas. It was determined that there had been a total of 7 Jewish victims. In the case of Vienna, it was determined that no Jewish or non-Jewish victims from Nazi concentration camps had been delivered to the anatomy institute. It is known that the bodies of Jewish victims were exploited by other institutions, but that needs to be the subject of a separate discussion.

In May 2005, I was contacted by Prof. Christoph Redies of the University of Jena. Redies, on becoming aware of the anatomy issue, undertook on his own to examine his department's history and collection, together with a historian, Michael Viebig. They discovered misbegotten specimens, which they documented and acknowledged. The Jena anatomical institute was the first known example of a university anatomy institute undertaking its own self-examination with expert outside historical input, without any external pressure.

Around the same time, unbeknownst to many of us, a German-born and educated physician-anatomist at the University of Michigan by the name of Dr. Sabine Hildebrandt, learned of the Pernkopf controversy, which provoked her interest. This resulted in the first attempt at a comprehensive history of anatomy in Nazi Germany in a series of three papers authored by Hildebrandt, which were published in 2009 in the journal, Clinical Anatomy. (Hildebrandt 2009a, b, c) That same year a controversy arose over a paper published in the same journal on the Berlin anatomist Hermann Stieve, who is known to have exploited the bodies of executed female political prisoners for his studies on the effect of emotional stress on the female reproductive organs; the chronic stress of the women being imprisoned, and the acute stress of being told the date of their impending execution. (Winkelmann and Schagen, 2009)

In December of that year, I was in contact with Prof. Redies and suggested that, given Dr. Hildebrandt's history of anatomy and the Stieve controversy, it was time for the German and Austrian anatomists to have a proper scholarly discussion on the issue. In a message dated December 9, 2009, Redies responded, in part:

"Your idea of a scholarly conference is a very good one. However, I believe that this conference should not only be a conference ABOUT German anatomists, but also a conference BY German anatomists. ... With the background of the three articles by Dr. Hildebrandt, I will write a letter to the executive board members of the Anatomische Gesellschaft to propose that a scholarly meeting on anatomy under the Nazi regime be held in conjunction with one of the annual meetings of the Anatomische Gesellschaft. I can hardly imagine that they will reject the idea of such a meeting, but let us see what happens."

The Gesellschaft accepted Prof. Redies' proposal. He organized a special symposium co-chaired by himself and Hildebrandt, which was held in Würzburg on October 29, 2010. At the Würzburg gathering the anatomists agreed that they needed to investigate their history, and collections, from the Nazi period.

The Würzburg symposium was a turning point. There was no longer denial and resistance. Thanks to the leadership of Prof. Redies, Prof. Hildebrandt and the Anatomische Gesellschaft, the silence had been broken.

And so it began. Prof. Hildebrandt wrote her book which is the first and only definitive history of anatomy under National Socialism. (Hildebrandt, 2016) Anatomists and historians began proper examinations of their own institutional history including their collection of specimens. Papers continue to be written and published.

Prof. Hildebrandt and I have been collaborating since 2009; mainly by internet and Skype. I have also had the honor of collaborating with her on papers and projects. We had our first face-to-face meeting at Starbucks in the Frankfurt railroad station en route to Würzburg. In 2015 Hildebrandt was invited to speak at the Faculty of Medicine of Washington University in St. Louis. The 
Washington University faculty had, for many years, held an annual event on the subject of medicine and the Holocaust. The 2015 event in St. Louis resulted in the conjunction of history, clinical reality and ethics exemplified by the anatomist/historian Hildebrandt, the noted nerve surgeon Prof. Susan Mackinnon, and her associate Andrew Yee, that ultimately led to today's event.

When informed by Prof. Hildebrandt of Prof. Mackinnon's and Andrew Yee's dilemma, given Mackinnon's description of her work, I suggested that the Jewish principle of Pikuach Nefesh or the saving of human life, may be applicable. It was subsequently agreed by all the parties involved to request a formal rabbinical opinion from Rabbi Polak and Prof. Michael Grodin of Boston University. Out of this came the first known rabbinical responsum addressing the ethical issues regarding the use of the images from the Pernkopf atlas. That historic responsum is known as the Vienna Protocol and includes consideration of how to deal with discovered human remains that are believed to be those of Jewish victims of the Holocaust. These issues formed the basis of a special international symposium of experts held at Yad Vashem in May 2017 which I had the honor of chairing. Contributors included Rabbi Polak and Prof. Hildebrandt. (Seidelman et al., 2017) It was informed by the work of Prof. Mackinnon and Andrew Yee.

While the Vienna Protocol is based on Jewish religious sources, it has universal application irrespective of the religion or ethnicity of the victims. It can be, and is being used in similar situations where remains of victims of genocide or human rights abuse are discovered.

I began this venture in an attempt to document the role played by the academic and professional elite of Germany and Austria in the medical crimes of the Third Reich. Contrary to the myth being perpetrated by the German medical profession after the war, the crimes were not the work of a few evil perpetrators on the margins of the profession but involved the most distinguished and respected leaders and scientists. The discovery of the role of university anatomy institutes and the specimens in the collections of the esteemed Max Planck Society are evidence of that role. But we are only at the beginning.

We live in an age of constant curricular change in medical faculties. Perhaps the greatest and most profound change in medical school curricula occurred in 1933, when many German universities and research institutes succumbed to the imposition of the philosophy and policies of the new Hitler regime. The ethos of medicine was transformed from the Hippocratic ethos of "do no harm" to the Nazi ethos that "harm is permissible in advancement of the policy of Volksgesundheit," the health of the nation.

74 years after the end of the war and the Shoah, we are only at the beginning of any understanding of what happened within the walls of those once esteemed institutions and organizations. It will probably be decades before we have any proper documentation. It is important that we have this pathological examination of such a huge transformation with such profound and tragic results.

I conclude with a personal reflection. A new, younger generation of scholars led by Prof. Hildebrandt and colleagues is pursuing research on this and related subjects. A majority of these scholars are in Germany and Austria and other European countries. Questions are being asked beyond the realms of anatomy or history or ethics that now include disciplines such as surgery and neurology and psychiatry. Most importantly, victims exploited by the Nazi regime are no longer forgotten, with more and more being discovered and identified and their memories honored; exemplified, in part, by the subjects portrayed in the Pernkopf atlas.

In the end, that is as much as one could hope for, for now.

\section{References}

Aly, Götz. 1988. "Forschen an Opfern. Das KaiserWilhelm-Institut für Hirnforschung und die "T4"." In: Aly, G. (ed.): Aktion T4 1939-1945. Die "Euthanasie"Zentrale in der Tiergartenstrasse 4, edited by Götz Aly, 153-159. Berlin: Edition Hentrich.

Angetter DC. Anatomical science at the University of Vienna 1938-45. Lancet. 2000; 355:1445-57.

Hildebrandt, Sabine. 2009a. "Anatomy in the Third Reich: An Outline, Part 1. National Socialist Politics, Anatomical Institutions, and Anatomists." Clinical Anatomy 22:883-893.

Hildebrandt, Sabine. 2009b. "Anatomy in the Third Reich: An Outline, Part 2. Bodies for Anatomy and Related Medical Disciplines.” Clinical Anatomy 22:894-905.

Hildebrandt, Sabine. 2009c. "Anatomy in the Third Reich: An Outline, Part 3. The Science and Ethics of Anatomy in 
National Socialist Germany and Postwar Consequences." Clinical Anatomy 22:906-915.

Hildebrandt S. 2016. The Anatomy of Murder: Ethical Transgressions and Anatomical Science during the Third Reich. New York: Berghahn Books.

Israel, Howard A., and William E. Seidelman. 1996. "Nazi Origins of an Anatomy Text: the Pernkopf Atlas." Journal of the American Medical Association 276(20):1633.

Redies, Christoph, Michael Viebig, Susanne Zimmermann, and Rosemarie Fröber. 2005. "Origin of the Corpses Received by the Anatomical Institute at the University of Jena During the Nazi Regime." The Anatomical Record (Part B: New Anat.) 285B:6-10

Seidelman, William E. 2012. "Dissecting the History of Anatomy in the Third Reich- 1989-2010: A Personal Account." Annals of Anatomy 194:228-236.

Seidelman, William E.; Elbaum, Lilka; Hildebrandt, Sabine (eds.), 2017. How to deal with Holocaust era human remains: recommendations arising from a special symposium. Recommendations/guidelines for the handling of future discoveries of human victims of Nazi terror, and "Vienna Protocol" for when Jewish or possibly-Jewish human remains are discovered, by Rabbi Joseph A. Polak. URL:

https://www.bu.edu/jewishstudies/research/medicine-andthe-holocaust/recommendations-for-the-discovery-ofjewish-remains-project/[last accessed 1/30/2020].

Ter Meulen, Volker. 2010. Rede des Präsidenten der Leopoldina bei der Einweihung der Gedenkstele am 1. Oktober 2009 in Halle (Saale). Nova Acta Leopoldina 22:7-10, also online accessed September 92014. http://www.leopoldina.org/uploads/tx leopublication/Prob eNALSu22.pdf

Weindling, Paul J. 2012. “"Cleansing” anatomical collections: The politics of removing specimens from anatomical collections 1988-1992." Annals of Anatomy 194:237-242.

Winkelmann A, Schagen U. 2009. Hermann Stieve's Clinical-Anatomical Research on Executed Women During the "Third Reich. Clinical Anatomy 22(2):163-171.

\begin{abstract}
About the Author
Dr. Seidelman is Emeritus Professor of Family and Community Medicine at the University of Toronto. He practiced family medicine in Vancouver, Hamilton, and Toronto Ontario in association with the University of British Columbia, McMaster and the University of Toronto. His clinical practice focused on the inner-city, HIV/AIDS and palliative and geriatric care. He was a member of the Board of Directors of Associated Medical Services of Ontario serving as President/CEO from 2002 to 2007. For the past forty years Dr. Seidelman has explored the history of the Third Reich with an emphasis on the role of academic medicine and research with a focus on the exploitation of the bodies of victims of Nazi terror by German/Austrian universities and research organizations. He has published numerous papers on the continuing legacy of Nazi medicine. In 2017, he chaired a special symposium, hosted by Yad Vashem, and the report of that symposium included the landmark Vienna Protocol authored by Rabbi Joseph Polak with the assistance of Prof. Michael Grodin of Boston University.
\end{abstract}

Prof.(Em) William Seidelman, M.D.

Department of Family and Community Medicine Temerty Faculty of Medicine, University Toronto Contact: billseidelman@gmail.com

\section{Image Credit}

The 1938 photo of a Faculty of Medicine assembly at the University of Vienna under its newly appointed dean, Prof. Eduard Pernkopf is licensed and used with permission of the Österreichische Nationalbibliothek (Austrian National Library, Vienna, Austria).

\section{Licensing}

The author has chosen to license this content under a Creative Commons Attribution, NonCommercial, NoDerivatives 4.0 International License.

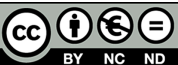




\section{Conflict of Interest Statement}

The Journal of Biocommunication Management Board and Editors believe that transparency in academic research is essential. Our JBC authors are now required to disclose any possible conflict of interest when submitting a manuscript. In accordance with the Journal of Biocommunication's editorial policy, no potential conflict of interest has been reported or declared by this author. 